\title{
Precipitating Factors for Diabetic Ketoacidosis among Patients with Type 1 Diabetes Mellitus: The Effect of Socioeconomic Status
}

\author{
Ahmed Hakim Al-Obaidi ${ }^{a} \quad$ Haider Ayad Alidrisi ${ }^{b} \quad$ Abbas Ali Mansour ${ }^{c}$ \\ ${ }^{a}$ Basrah Directorate of Health, Basrah, Iraq; ${ }^{b}$ Faiha Specialized Diabetes, Endocrine and Metabolism Center (FDEMC), \\ Diabetes, Endocrine and Metabolism Division, Department of Medicine, College of Medicine, University of Basrah, \\ Basrah, Iraq; ${ }^{C}$ Faiha Specialized Diabetes, Endocrine and Metabolism Center (FDEMC), Chair Diabetes, Endocrine and \\ Metabolism Division, Department of Medicine, College of Medicine, University of Basrah, Basrah, Iraq
}

\section{Keywords}

Diabetic ketoacidosis - Type 1 diabetes mellitus .

Socioeconomic factors

\begin{abstract}
Background: Diabetic ketoacidosis (DKA) is one of the lifethreatening acute complications of diabetes mellitus that mainly occurs in type 1 diabetes mellitus (T1DM). This study aimed to determine the socioeconomic factors associated with DKA in patients with T1DM in Basrah. Methods: A crosssectional study including patients with T1DM who were admitted due to DKA or any other complaint in any of the teaching hospitals in Basrah, from February to October 2017. Data collection from each patient or their parents using a questionnaire was designed to capture personal, social, and disease-related factors. Results: One hundred forty-seven patients were involved in this study. They were compared with different factors to assess correlations with the risk of DKA. Younger age, underweight, being without a job, low personal and/or mother educational level, travel, home glucose monitoring less than 7 times a week, uncontrolled $\mathrm{HbA}_{1 \mathrm{c}}$ and insulin stoppage as a cause of DKA regardless of the reasons to stop were associated with an increased risk of
\end{abstract}

\begin{tabular}{ll}
\hline KARGER & $\begin{array}{l}\text { C } 2019 \text { The Author(s) } \\
\text { Published by S. Karger AG, Basel }\end{array}$ \\
E-Mail karger@karger.com & This article is licensed under the Creative Commons Attribution- \\
www.karger.com/ijd & $\begin{array}{l}\text { NonCommercial-NoDerivatives 4.0 International License (CC BY- } \\
\text { NC-ND) (http://www.karger.com/Services/OpenAccessLicense). } \\
\text { Usage and distribution for commercial purposes as well as any dis- } \\
\text { tribution of modified material requires written permission. }\end{array}$
\end{tabular}

DKA. On the other hand, own home, availability of a glucometer for checking glucose, basal-bolus insulin regimen, insulin supply, and education at a tertiary center, correct injection technique whoever injected the insulin and dietary adherence, all were associated with a decreased risk of DKA. Other factors like gender, marital status, smoking status, father educational level, residency, income, personal home area, the frequency of $\mathrm{HbA}_{1 \mathrm{c}}$ checking, and family history of diabetes were not associated with a significant effect on the DKA risk. Conclusions: Multiple socioeconomic factors interact to play a vital role in the development of DKA among patients with T1DM in Basrah.

(๑) 2019 The Author(s)

Published by S. Karger AG, Basel

Diabetic ketoacidosis (DKA) is one of the life-threatening acute complications of diabetes mellitus (DM) that mainly occurs in type 1 diabetes mellitus (T1DM) patients. It tends to present under stressful conditions or in association with illnesses that feature metabolic decompensation [1].

The prevalence of T1DM is increasing worldwide [2]. DKA was universally fatal, especially before the days of insulin in the 1920s; after that, the overall mortality de- 
creased to relatively low figures, but there is still the potential of case fatality from DKA either from acidosis or as a complication of the therapy [3].

Inequalities in the prevalence of diabetes and its complications by socioeconomic status (SES) have been described in many settings $[4,5]$, and this has its effect on subsequent mortality [4]. Various studies have addressed the relation between lower SES and mortality or the development of chronic conditions such as DM, cardiovascular disease, and cancer [6]. Potential explanations include differences in the prevalence of risk factors and access to and use of medical services [5]. Socioeconomic differences in longer-term outcomes appear to be more marked than in processes of care as reflected by disease management measures in several health care systems [5].

There is some compelling evidence for an association between low SES, adverse health outcomes and DM-related knowledge for persons with diabetes and other chronic conditions [6]. Since self-care is essential for the achievement of successful outcomes in T1DM, access to proper health care that facilitates the patient adoption of the most effective treatment regimens is also crucial $[4,6]$.

The persistence of a socioeconomic health gradient in the general population is well documented, and there is considerable evidence that the least well off in society have a reduced life expectancy and increased morbidity compared with the affluent [4].

While effective therapies are available for managing diabetes and preventing or treating its complications, these are underutilized, particularly among persons of low SES [6].

The practice of self-monitoring of blood glucose (SMBG), as a voluntary behavior among patients with T1DM, is not satisfactorily implemented. There is a significant gap between recommended SMBG utilization and real-world practice [7]. The intensive therapy to control glucose levels in adolescents effectively delays the onset and slows the progression of diabetic complications [8]. Unfortunately, intensive treatment doubles a person's risk of becoming overweight [9].

Research shows that recurrent DKA rates are dependent on medical services and socioeconomic circumstances especially in adolescents [10]. The effects of low SES on patients with known T1DM include insulin omission, poor metabolic control, previous episodes of DKA, gastroenteritis with persistent vomiting and inability to maintain hydration, psychiatric (including eating) disorders, challenging social and family circumstances, and limited access to medical services [11].

Poor adherence to insulin therapy is the leading cause of recurrent DKA in T1DM patients. Several behavioral, socioeconomic, psychosocial, and educational factors lead to poor compliance. The recognition of these factors and the institution of culturally appropriate interventions and education programs might reduce DKA recurrence in minority populations [12].

\section{The Aim of the Study}

To determine the socioeconomic factors that may precipitate DKA in patients with T1DM in Basrah.

\section{Patients and Methods}

This was a cross-sectional study involving patients with T1DM who were admitted to Basrah Teaching Hospitals, between February and October 2017.

Patients included in the study were T1DM patients who were admitted with any complaint including DKA. T1DM was defined as an onset of diabetes before the age of 35 years and permanent insulin treatment initiated within 1 year of diagnosis [13]. DKA was defined as a tetrad of blood glucose $>200 \mathrm{mg} / \mathrm{dL}(11 \mathrm{mmol} / \mathrm{L})$, ketonemia and ketonuria, venous $\mathrm{pH}<7.3$ and/or bicarbonate $<15$ $\mathrm{mmol} / \mathrm{L}$ [14]. Patients and/or their relatives were asked about the number of previous DKA episodes (depending on hospital records or records available with patients) and were subjected to specific questionnaires designed to capture personal, social, and diseaserelated factors. A written informed consent had been taken from patients or their relative if they were under 18 years old. Basrah University gave ethical approval for the study.

Patients excluded were patients with newly diagnosed T1DM, persistent altered mental status, and those not interested in research.

Patients' weight was measured with bare feet and light clothes, and the body mass index (BMI) was then calculated as body weight in $\mathrm{kg} /$ (height in meters) $^{2}$. The patients were classified according to WHO criteria ( $<18.5$ underweight, $18.5-24.9$ normal, $\geq 25$ overweight) [15].

Ion exchange high-performance liquid chromatography using a Biorad D10 measured the glycated hemoglobin $\left(\mathrm{HbA}_{1 \mathrm{c}}\right)$.

Every patient was assessed for personal and social factors: age, gender, BMI, marital status, job, personal and parental educational level (whether they had completed 6 stages of study or not, which means completing primary school or not, which is the lowest grade of graduation in our country), residency (urban and rural), smoking status, history of travel preceding the DKA, 1st-degree relative with diabetes, the family income, home (own, rent, or slum), occupancy and home personal area (area/person in squared meters). Other factors like from where the patient received his insulin and education about his disease, dietary adherence, who injected the insulin and whether it was done with the correct technique (by asking them to inject one of the insulin doses and observing), and whether the patient had stopped his insulin and the reason behind that (feeling sick, lack of supply, and no specific reason).

Disease-related factors in the form of T1DM duration, insulin regimen (basal bolus, premixed, or bolus only), the cause of the
Precipitating Factors for Diabetic

Ketoacidosis among Patients with T1DM
Int J Diabetes Metab 2019;25:52-60

DOI: $10.1159 / 000499839$ 
Table 1. General characteristics of the study DKA patients $(n=147)$

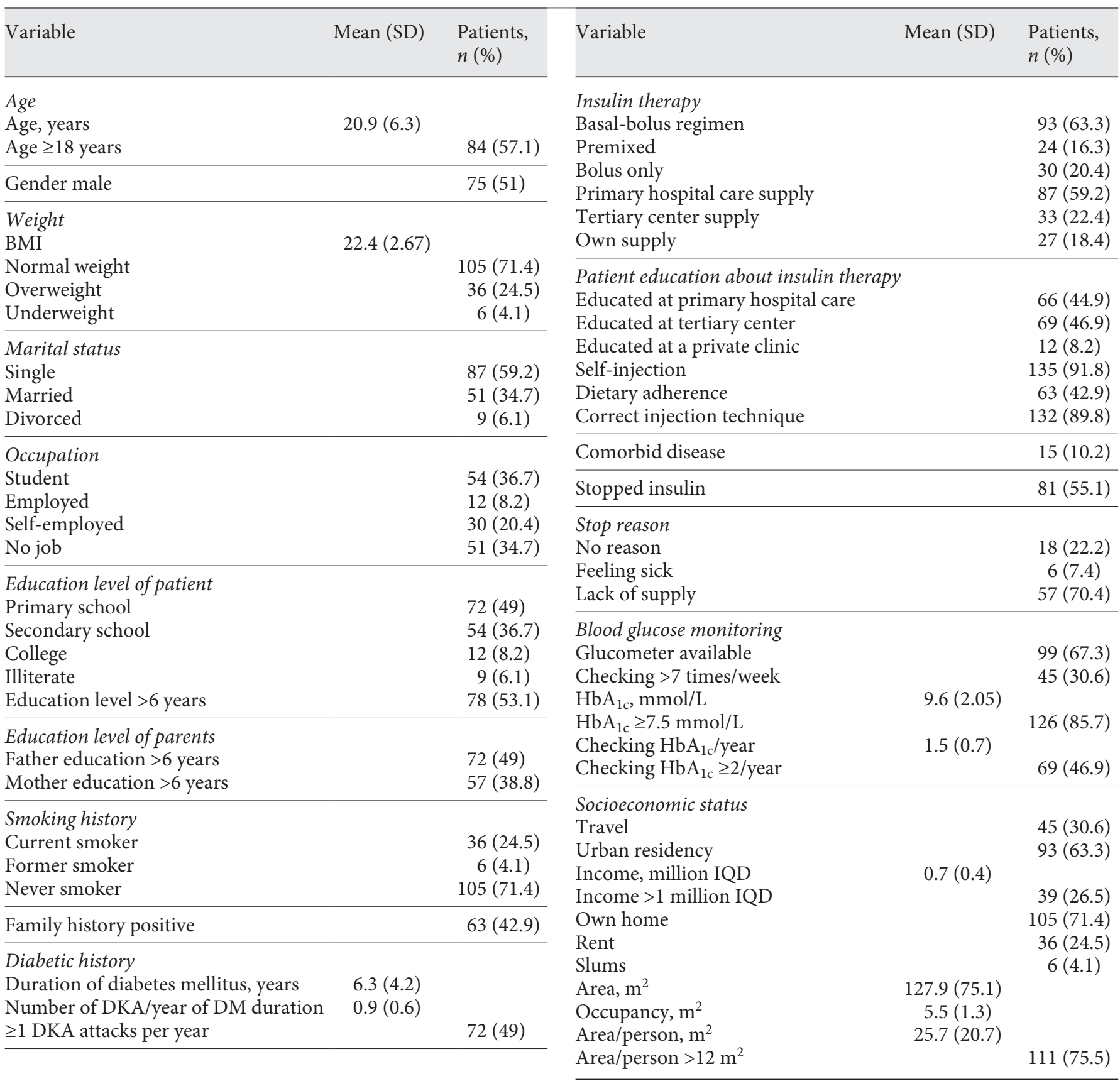

previous DKA (missed insulin dose, illness-like infection, or no specific reason), comorbid diseases, last $\mathrm{HbA}_{1 \mathrm{c}}$ within 3 months, glucometer availability, and frequencies of home glucose and $\mathrm{HbA}_{1 \mathrm{c}}$ checking.

Data collected from the questionnaires were analyzed using the Statistical Package for Social Sciences (SPSS) software version 22.0. Data are presented as a mean \pm standard deviation in the case of quantitative variables and as absolute numbers (per- centage) in the case of qualitative variables with statistical analysis carried out. An independent Student $t$ test was used to study the correlation between DKA frequency per year and the study factors. DKA frequency per year was divided into two categories using a cut-off of 1 DKA per year, and the odds for having 1 or more DKA episodes per year $(\geq 1 \mathrm{DKA} /$ year $)$ were measured using univariate analysis. The $p$ value of less than 0.05 was considered significant. 


\section{Results}

A total of 147 patients with T1DM consisted of 75(51\%) males and $72(49 \%)$ females. The mean age was $20.9 \pm 6.3$ years with the oldest age of 35 years, and the youngest age was 14 years. The mean $\mathrm{HbA}_{1 \mathrm{c}}$ was $9.6 \pm 2.05 \%$, with the majority of the patients $(126,85.7 \%)$ having $\mathrm{HbA}_{1 \mathrm{c}} \geq 7.5$ $\mathrm{mmol} / \mathrm{L}$ and only $21(14.3 \%)$ with $\mathrm{HbA}_{1 \mathrm{c}}<7.5 \mathrm{mmol} / \mathrm{L}$.

The mean for the frequency of DKA episodes per year was $0.9 \pm 0.6$ episodes/year with a maximum of 3 episodes/year and a minimum of 0.18 episodes/year. Seventy-two (49\%) patients had $\geq 1 \mathrm{DKA} /$ year. Ninety-three $(63.3 \%)$ patients were living in an urban area. One hundred and five (71.4\%) patients lived in their own home.

The remaining general characteristics of the study including personal, socioeconomic, and disease-related factors are summarized in Table 1.

When we assessed the correlation between the frequency of DKA with the disease-related factors as shown in Table 2 and correlations of these factors with the risk of $\geq 1 \mathrm{DKA} /$ year as shown in Figure 1, patients on a basal-bolus insulin regimen had a significantly lower frequency of DKA and were followed by premixed insulin, with a significant highest frequency in those on bolus only; basal bolus appeared protective against DKA (OR $0.2,95 \%$ CI $0.1-0.4, p<0.0001$ ). As a cause of the previous episodes, missing of insulin dosing and DKA with no specific reason were associated with a significantly higher frequency of DKA; missing of insulin dosing had an increased DKA risk (OR 4.6, $95 \%$ CI 2.2-9.8, $p<0.0001)$. Patients with uncontrolled $\mathrm{HbA}_{1 \mathrm{c}}$ had a significantly higher DKA frequency (for the cohort with uncontrolled $\mathrm{HbA}_{1 \mathrm{c}}$, OR $2.3,95 \% \mathrm{CI}$ $1.9-2.8, p<0.0001)$. Patients who had glucometers and used to check their home glucose 7 or more times per week appeared to have a significantly lower DKA frequency, having the glucometer associated with a lower DKA risk (OR $0.29,95 \%$ CI $0.14-0.6, p<0.001$ ), but on the other hand home glucose checking less than 7 times per week increased the DKA risk (OR 3.9, 95\% CI 1.8$8.4, p=0.0002)$, while checking $\mathrm{HbA}_{1 \mathrm{c}}$ frequently and the presence of comorbid diseases had no significant effect on DKA frequency.

Personal and social factors also had a significant effect on DKA frequency, as shown in Table 3, and the risk of $\geq 1$ DKA/year, shown in Figure 1. Patients of 18 years or older and overweight had significantly lower DKA frequencies, younger and underweight patients were at a higher $\geq 1 \mathrm{DKA}$ /year risk (OR 5.2, 95\% CI 2.5-10.7, $p<$ 0.0001 ), with OR $2.1,95 \%$ CI $1.7-2.5$, and $p=0.012$ for younger and underweight patients, respectively. Gender, marital status, and smoking status did not have an effect.

Being employed appeared to have a protective effect against DKA as compared to students and patients with no job, as all patients without a job had a higher $\geq 1$ DKA/year risk (OR 3.3, 95\% CI 1.5-7.2, $p=0.001$ ). Patient, mother, and father education levels had a significant effect on DKA frequency, completion of primary education ( $\geq 6$ years) in the patients or parents was associated with a lower frequency of DKA, the lowest especially with patient and mother education and less low with father education. The risks in patients with $<6$ years of education or with a mother with a similarly low educational level for having $\geq 1 \mathrm{DKA}$ /year were OR 3.5

Table 2. Correlation between DKA and diabetes-related factors

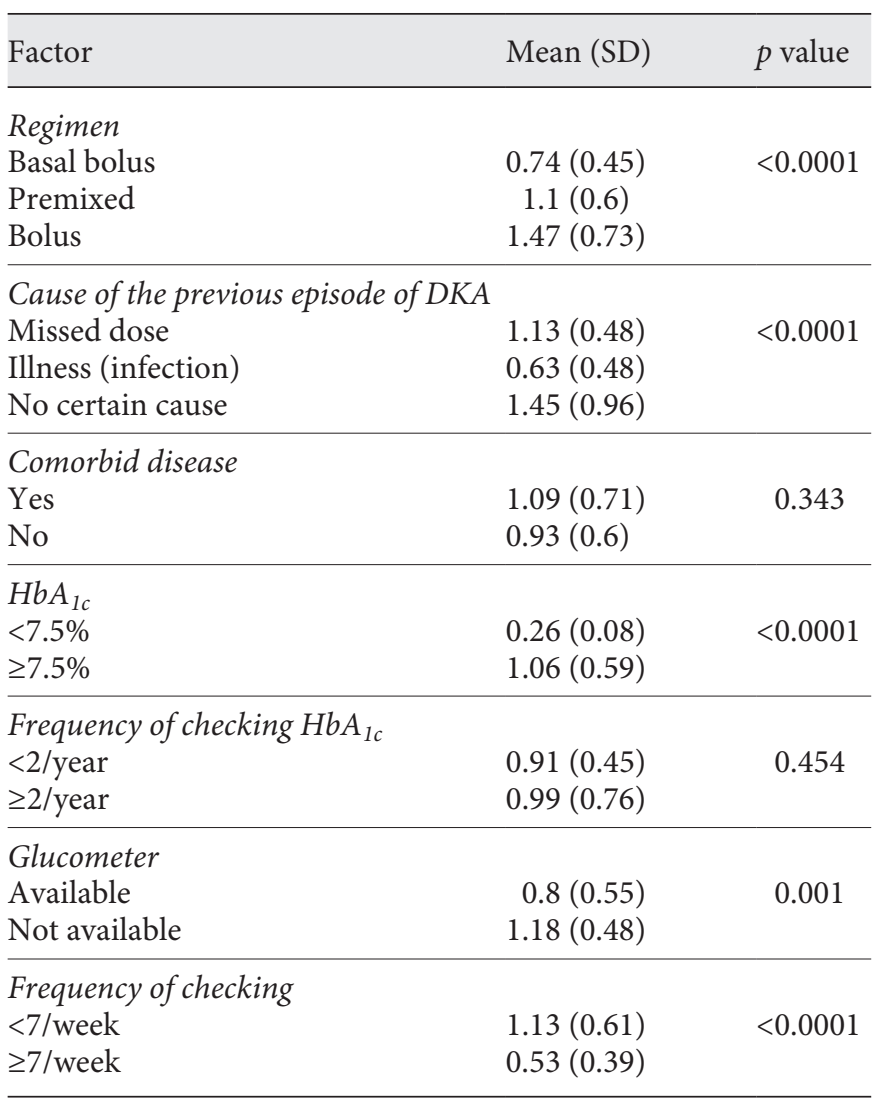

Fig. 1. Relation of the significant study factors with the $1 \mathrm{DKA} /$ year risk. The odds ratio (OR) is given for the first predictor in each category. ${ }^{*}$ OR for a cohort of $<1 \mathrm{DKA}$ year. ${ }^{* *}$ OR for a cohort with $\geq 1 \mathrm{DKA}$ /year. DKA, diabetic ketoacidosis; CI, confidence interval; BMI, body mass index; $\mathrm{BB}$, basic bolus; $\mathrm{A} 1 \mathrm{C}$, hemoglobin $\mathrm{A}_{1 \mathrm{c}} ; \mathrm{DM}$, diabetes mellitus.

(For figure see next page.) 


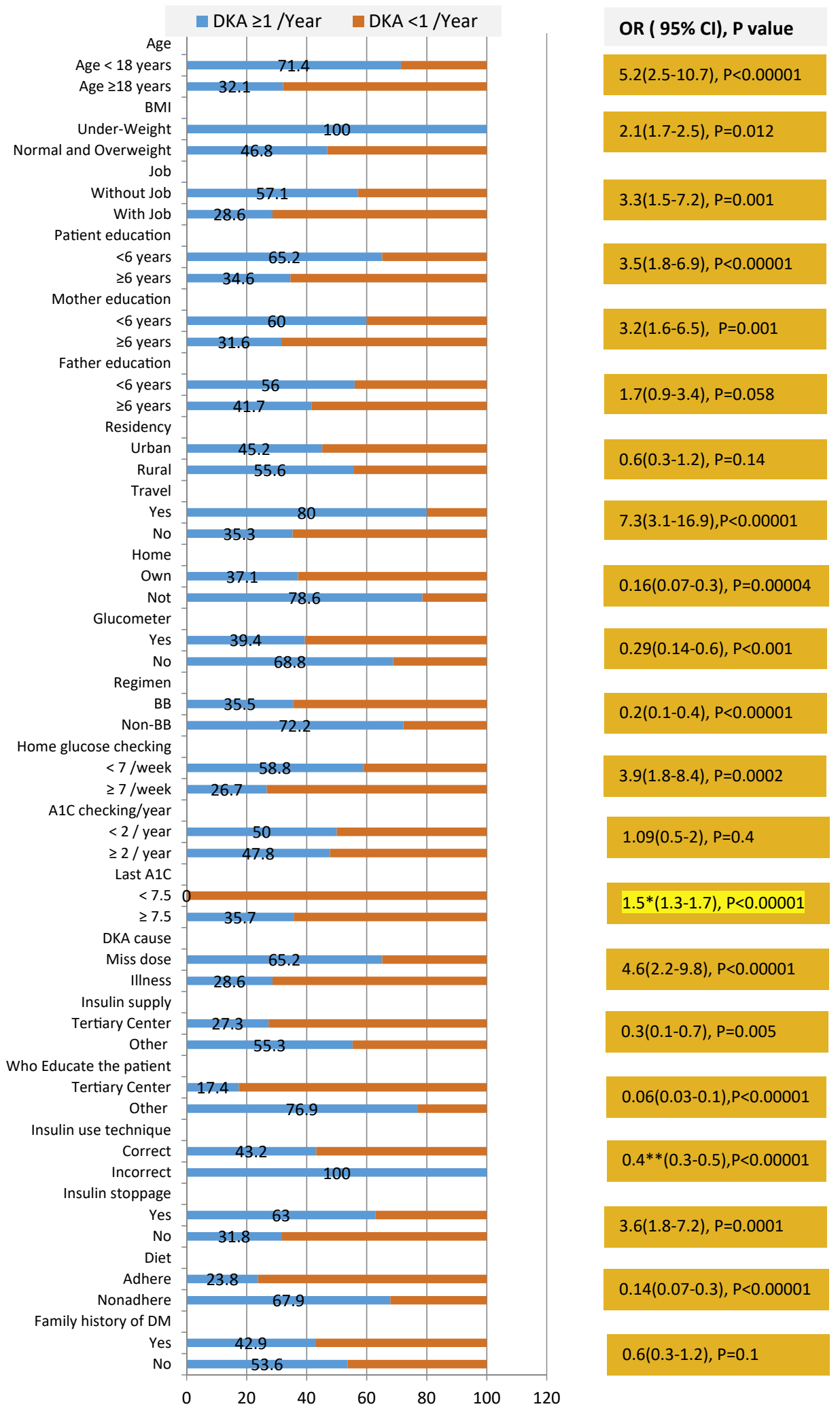


Table 3. Correlation between DKA and personal and social factors

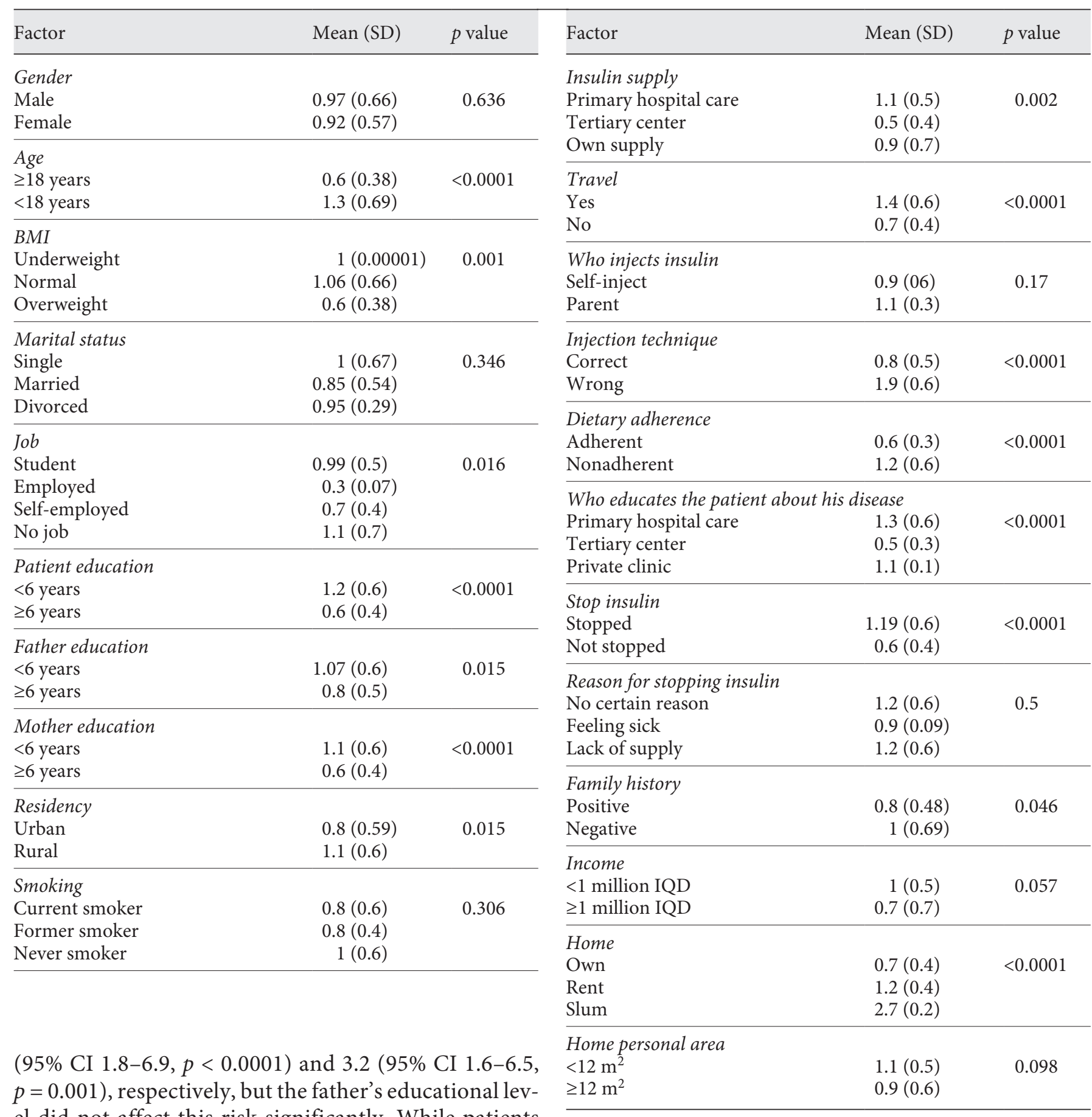

el did not affect this risk significantly. While patients with urban residency were less likely to have DKA episodes, there was no significant effect of residency on the $\geq 1 \mathrm{DKA} /$ year risk. While patients who were living in their own homes had a lower DKA frequency and less $\geq 1$ DKA/year risk with an OR of 0.16 (95\% CI 0.07-0.3, $p=0.0004)$, personal home area and family income did not affect the frequency of DKA episodes. Travel his- 
technique, helpers who had been educated at and received their insulin from a tertiary center, and adherence to diet caused significantly lower DKA episode frequencies and lower risks for $\geq 1 \mathrm{DKA} /$ year (OR 0.4, 95\% CI $0.3-0.5, p<0.0001$; OR $0.06,95 \%$ CI $0.03-0.1, p<$ 0.0001 ; OR $0.3,95 \%$ CI $0.1-0.7, p=0.005$, and OR 0.14 , $95 \%$ CI $0.07-0.3, p<0.0001$, respectively). On the other hand, stopping of insulin had an increased DKA episode frequency, with a higher risk for $\geq 1 \mathrm{DKA}$ /year (OR 3.6, $95 \%$ CI 1.8-7.2, $p=0.0001$ ) regardless of the reason for insulin stoppage which was not significant. Finally, patients with a family history of diabetes had a slightly lower DKA episode frequency but with no significant risk for $\geq 1 \mathrm{DKA} /$ year.

\section{Discussion}

In this study, we explored the critical factors associated with DKA in our area.

There was a significant correlation between age and risk of developing DKA where those with age $<18$ years were at a higher risk, which goes in accordance with previous studies $[3,16]$. Teenage at diabetes onset was related to an elevated incidence of DKA; less parental monitoring for adolescents may lead to a deterioration of metabolic control in this group, and they are more likely to escape parental control; thus, detection or reporting hyperglycemia symptoms may be delayed. On the other hand, endocrine changes associated with puberty lead to greater insulin resistance [17].

Patients with underweight carry a high risk of developing DKA in this study. A higher BMI is associated with more residual $\beta$-cell function and a decrease in the incidence of DKA at the onset of development of T1DM [18]. That was consistent with two previous studies reporting on the association between BMI and a diagnosis of DKA, which showed a higher frequency of DKA in those with a lower BMI $[15,19]$.

The study did not show a significant difference between males and females in contrast to other studies which concluded that there was a predominance of females with DKA $[16,20]$.

It was found that the initiation of a suitable and effective insulin regimen was associated with a reduced DKA rate $[21,22]$, as found in this study where the lowest DKA was seen among those patients using a basal-bolus insulin regimen. This may be explained by the fact that basal insulin is important to provide cells with a continuous glucose supply to burn for energy and prevent lipolysis [23]. And that also explained that an intentionally or unintentionally missed insulin dose was the most common cause of previous DKA episodes in this study, which was identical to the results of a study done by Randall et al. [12]. Insulin discontinuation has long been recognized as an important precipitating cause of DKA in retrospective studies [24].

The major finding of our study was that almost all admissions for DKA were associated with markedly elevated $\mathrm{HbA}_{1 c}$ levels at presentation. The findings of very high $\mathrm{HbA}_{1 \mathrm{c}}$ levels in this study suggest that, in our setting, DKA occurs in the background of poor control, and that is similar to results from other studies [25, 26].

Studies have shown a direct correlation between $\mathrm{SMBG}$ and improved $\mathrm{HbA}_{1 \mathrm{c}}$ levels and a reduced DKA rate [2729]. This is identical to what is found in this study with a reduction in the number of DKA among those who frequently used SMBG compared to those who used SMBG infrequently or not at all.

In our study the DKA risk was higher among the nonemployed in comparison to patients with stable employment, that association found to be nonsignificant in a previous study [12]; the explanation behind that may be related to the high education level of those with stable employment where all of them had undergone education of $>6$ years. Furthermore, the regular daily activities of employed patients might have resulted in the lower DKA risk in those patients.

The low educational level of patients and their parents was significantly associated with the development of DKA in our study. Other studies reported an influence of parental education: having a mother with higher than secondary education was protective against developing DKA in Lithuania [30]. A second study set in Germany showed that children from families in which parents had less than 9 years of education had a significantly increased risk of severe DKA [31].

The study showed that living in rural or urban areas had no significant effect on rates of DKA. In Finland, there was no difference in the frequency of DKA between families living in a city, town, or suburb compared with those living in a village or rural areas [32].

The study showed a significant correlation between travel and an increased risk of DKA, and this can be explained by the difficulty in controlling blood sugar and insulin while traveling together with changes in activity levels and diet while traveling, especially across multiple time zones [33].

We did not find a significant correlation between smoking and the risk of DKA, in contrast to the previous study which showed that large percentages of subjects with insulin noncompliance were smokers and that led to an increased risk of DKA [34].
Al-Obaidi/Alidrisi/Mansour 
Patient education and supply of insulin from a tertiary center appeared to have a protective effect against DKA in this study. The presence of an identifiable primary care provider lowered the risk of DKA and was confirmed by a previous study carried out by the Department of Emergency Medicine, Maricopa Medical Center, Phoenix, AZ, USA [35]. A part of patient education is the correct insulin administration which has been found to reduce the DKA risk in this study and in another [36]. Injecting too deeply could deliver insulin to the muscle, where it may be absorbed too quickly. Injecting too shallowly deposits insulin in the skin, which is painful and reduces complete absorption [33]. Nonadherence to dietary instruction has also been associated with a higher DKA risk in this study, which was similar to what was found by another study [34].

In a study from Kuwait [37], it was reported that there was an effect of a family history of diabetes on presentation with DKA, which may be explained by the increased awareness of the family about diabetes and the administration of insulin therapy. However, in this study, family history of diabetes did not show a significant effect on DKA risk, a finding comparable to a German study which failed to find a significant association with a family history of either T1DM or T2DM in siblings, parents, or grandparents [31].

Family income had no significant effect on the risk of presenting with DKA in our study; for us, that could be explained by insulin being available at governmental hospitals or primary hospital care with low supported cost. This result was supported by two European studies [32, 38]. In contrast, a Canadian study, which was adjusted for gender and age, showed that those from a family in the two lowest quintiles of income were associated with an increased risk of DKA [39].

\section{Conclusions}

The results of this study provided evidence that multiple socioeconomic factors interact to play a vital role in the development of DKA among patients with T1DM in Basrah.

Younger age, underweight, being without a job, low personal and/or mother educational level, travel, home glucose monitoring less than 7 times a week, uncontrolled $\mathrm{HbA}_{1 c}$, and insulin stoppage as a cause of DKA regardless of the reasons to stop were associated with an increased risk of DKA. On the other hand, own home, availability of a glucometer for checking glucose, basal-bolus insulin regimen, insulin supply, and education at a tertiary center, correct injection technique whoever injected the insulin, and dietary adherence were associated with a decreased risk of DKA.

\section{Acknowledgment}

Great thanks are due to the medical and paramedical staff who aided in this study.

\section{Statement of Ethics}

The ethical committee of Basrah University approved the study. A written informed consent had been taken from patients or their relatives if they were under 18 years old.

\section{Disclosure Statement}

There is no conflict of interest.

\section{Author Contributions}

The authors contributed equally to the article.

\section{References}

1 Almalki MH, Buhary BM, Khan SA, Almaghamsi A, Alshahrani F. Clinical and biochemical characteristics of diabetes ketoacidosis in a tertiary hospital in Riyadh. Clin Med Insights Endocrinol diabetes. 2016 May;9:7-11.

2 Prevention of diabetes mellitus. Report of a WHO Study Group. World Health Organ Tech Rep Ser. 1994;844:1-100.

3 Ellemann K, Soerensen JN, Pedersen L, Edsberg B, Andersen OO. Epidemiology and treatment of diabetic ketoacidosis in a community population. Diabetes Care. 1984 NovDec;7(6):528-32.
4 Scott A, Chambers D, Goyder E, O'Cathain A. Socioeconomic inequalities in mortality, morbidity and diabetes management for adults with type 1 diabetes: A systematic review. PLoS One. 2017 May;12(5):e0177210.

5 Wild SH, McKnight JA, McConnachie A, Lindsay RS; Glasgow and Lothian Diabetes Register Data Group. Socioeconomic status and diabetes-related hospital admissions: a cross-sectional study of people with diagnosed diabetes. J Epidemiol Community Health. 2010 Nov;64(11):1022-4.
6 Brown AF, Ettner SL, Piette J, Weinberger M, Gregg E, Shapiro MF, et al. Socioeconomic position and health among persons with diabetes mellitus: a conceptual framework and review of the literature. Epidemiol Rev. 2004; 26(1):63-77.

7 Qin ZY, Yan JH, Yang DZ, Deng HR, Yao B, Weng JP; Guangdong Type 1 Diabetes Mellitus Translational Study Group. Behavioral Analysis of Chinese Adult Patients with Type 1 Diabetes on Self-monitoring of Blood Glucose. Chin Med J (Engl). 2017 Jan;130(1):3944.
Precipitating Factors for Diabetic

Ketoacidosis among Patients with T1DM
Int J Diabetes Metab 2019;25:52-60 DOI: $10.1159 / 000499839$ 
8 Nathan DM, Genuth S, Lachin J, Cleary P, Crofford O, Davis M, et al.; Diabetes Control and Complications Trial Research Group. The effect of intensive treatment of diabetes on the development and progression of longterm complications in insulin-dependent diabetes mellitus. N Engl J Med. 1993 Sep; 329(14):977-86.

9 Shulman R, Stukel TA, Miller FA, Newman A, Daneman D, Wasserman JD, et al. Low socioeconomic status is associated with adverse events in children and teens on insulin pumps under a universal access program: a population-based cohort study. BMJ Open Diabetes Res Care. 2016 Jun;4(1):e000239.

10 Al-Hayek AA, Robert AA, Braham RB, Turki AS, Al-Sabaan FS. Frequency and associated risk factors of recurrent diabetic ketoacidosis among Saudi adolescents with type 1 diabetes mellitus. Saudi Med J. 2015 Feb;36(2):216-20.

11 Wolfsdorf JI, Allgrove J, Craig ME, Edge J, Glaser N, Jain V, et al.; International Society for Pediatric and Adolescent Diabetes. ISPAD Clinical Practice Consensus Guidelines 2014. Diabetic ketoacidosis and hyperglycemic hyperosmolar state. Pediatr Diabetes. 2014 Sep; 15(S20 Suppl 20):154-79.

12 Randall L, Begovic J, Hudson M, Smiley D, Peng L, Pitre N, et al. Recurrent diabetic ketoacidosis in inner-city minority patients: behavioral, socioeconomic, and psychosocial factors. Diabetes Care. 2011 Sep;34(9):18916.

13 Menke A, Orchard TJ, Imperatore G, Bullard KM, Mayer-Davis E, Cowie CC. The prevalence of type 1 diabetes in the United States. Epidemiology. 2013 Sep;24(5):773-4.

14 Wolfsdorf J, Craig ME, Daneman D, Dunger D, Edge J, Lee W, et al. Diabetic ketoacidosis in children and adolescents with diabetes. Pediatr Diabetes. 2009 Sep;10 Suppl 12:118-33.

15 Physical status: the use and interpretation of anthropometry. Report of a WHO Expert Committee. World Health Organ Tech Rep Ser. 1995;854:1-452.

16 Smaldone A, Honig J, Stone PW, Arons R, Weinger K. Characteristics of California children with single versus multiple diabetic ketoacidosis hospitalizations (1998-2000). Diabetes Care. 2005 Aug;28(8):2082-4.

17 Amiel SA, Sherwin RS, Simonson DC, Lauritano AA, Tamborlane WV. Impaired insulin action in puberty. A contributing factor to poor glycemic control in adolescents with diabetes. N Engl J Med. 1986 Jul;315(4): 215-9.
18 Redondo MJ, Rodriguez LM, Escalante M, O'Brian Smith E, Balasubramanyam A, Haymond MW. Beta cell function and BMI in ethnically diverse children with newly diagnosed autoimmune type 1 diabetes. Pediatr Diabetes. 2012 Nov; 13(7):564-71.

19 Hekkala A, Reunanen A, Koski M, Knip M, Veijola R; Finnish Pediatric Diabetes Register. Age-related differences in the frequency of ketoacidosis at diagnosis of type 1 diabetes in children and adolescents. Diabetes Care. 2010 Jul;33(7):1500-2.

20 Levine BS, Anderson BJ, Butler DA, Antisdel JE, Brackett J, Laffel LM. Predictors of glycemic control and short-term adverse outcomes in youth with type 1 diabetes. J Pediatr. 2001 Aug;139(2):197-203.

21 Morris AD, Boyle DI, McMahon AD, Greene SA, MacDonald TM, Newton RW. Adherence to insulin treatment, glycaemic control, and ketoacidosis in insulin-dependent diabetes mellitus. The DARTS/MEMO Collaboration. Diabetes Audit and Research in Tayside Scotland. Medicines Monitoring Unit. Lancet. 1997 Nov;350(9090):1505-10.

22 Walker M, Marshall SM, Alberti KG. Clinical aspects of diabetic ketoacidosis. Diabetes Metab Rev. 1989 Dec;5(8):651-63.

23 Scheiner G. Selecting an insulin program for type 1 diabetes. Diabetes Self Manag. 2003; 20(5):54-6, 58.

24 Umpierrez GE, Kelly JP, Navarrete JE, Casals MM, Kitabchi AE. Hyperglycemic crises in urban blacks. Arch Intern Med. 1997 Mar; 157(6):669-75.

25 Henderson DC, Cagliero E, Copeland PM, Louie PM, Borba CP, Fan X, et al. Elevated hemoglobin Alc as a possible indicator of diabetes mellitus and diabetic ketoacidosis in schizophrenia patients receiving atypical antipsychotics. J Clin Psychiatry. 2007 Apr; 68(4):533-41.

26 O Ekpebegh C, Longo-Mbenza B, BlancoBlanco E. Glycosylated haemoglobin is markedly elevated in new and known diabetes patients with hyperglycaemic ketoacidosis. Afr Health Sci. 2014 Sep;14(3):526-32.

27 Norris SL, Lau J, Smith SJ, Schmid CH, Engelgau MM. Self-management education for adults with type 2 diabetes: a meta-analysis of the effect on glycemic control. Diabetes Care. 2002 Jul;25(7):1159-71.

28 Polonsky WH, Earles J, Smith S, Pease DJ, Macmillan M, Christensen R, et al. Integrating medical management with diabetes selfmanagement training: a randomized control trial of the Diabetes Outpatient Intensive Treatment program. Diabetes Care. 2003 Nov;26(11):3048-53.
29 Sheppard P, Bending JJ, Huber JW. Pre- and post-prandial capillary glucose self-monitoring achieves better glycaemic control than pre-prandial only monitoring. Pract Diabetes Int. 2005;22(1):15-22.

30 Sadauskaite-Kuehne V, Samuelsson U, Jasinskiene E, Padaiga Z, Urbonaite B, Edenvall $\mathrm{H}$, et al.; DEBS Study Group. Severity at onset of childhood type 1 diabetes in countries with high and low incidence of the condition. Diabetes Res Clin Pract. 2002 Mar; 55(3):247-54.

31 Rosenbauer J, Icks A, Giani G. Clinical characteristics and predictors of severe ketoacidosis at onset of type 1 diabetes mellitus in children in a North Rhine-Westphalian region, Germany. J Pediatr Endocrinol Metab. 2002 Sep-Oct;15(8):1137-45.

32 Komulainen J, Lounamaa R, Knip M, Kaprio EA, Akerblom HK; Childhood Diabetes in Finland Study Group. Ketoacidosis at the diagnosis of type 1 (insulin dependent) diabetes mellitus is related to poor residual beta cell function. Arch Dis Child. 1996 Nov;75(5): 410-5.

33 Patient education. Diabetes mellitus type 1: insulin treatment [Internet] [cited $2017 \mathrm{Apr}$ 25]. Available from: https://www.uptodate. $\mathrm{com} /$ contents/diabetes-mellitus-type-1-insulin-treatment-beyond-the-basics

34 Yan JH, Yang DZ, Deng HR, Li J, Weng JP. [Incidence and related risk factors of diabetic ketoacidosis in Guangdong type 1 diabetics]. Zhonghua Yi Xue Za Zhi. 2013 Mar;93(12): 897-901.

35 Horwitz DA, Schwarz ES, Scott MG, Lewis LM. Emergency department patients with diabetes have better glycemic control when they have identifiable primary care providers. Acad Emerg Med. 2012;19(6):650-5.

36 Spollett G, Edelman SV, Mehner P, Walter C, Penfornis A. Improvement of Insulin Injection Technique: Examination of Current Issues and Recommendations. Diabetes Educ. 2016 Aug;42(4):379-94.

37 Abdul-Rasoul M, Al-Mahdi M, Al-Qattan H, Al-Tarkait N, Alkhouly M, Al-Safi R, et al. Ketoacidosis at presentation of type 1 diabetes in children in Kuwait: frequency and clinical characteristics. Pediatr Diabetes. 2010 Aug; 11(5):351-6.

38 Blanc N, Lucidarme N, Tubiana-Rufi N. [Factors associated with childhood diabetes manifesting as ketoacidosis and its severity]. Arch Pédiatrie. 2003;10(4):320-5. French.

39 Bui H, To T, Stein R, Fung K, Daneman D. Is diabetic ketoacidosis at disease onset a result of missed diagnosis? J Pediatr. 2010 Mar; 156(3):472-7. 